\title{
Computational Modeling for Thermal Analysis of AV1 Diesel Engine Valve using FEM
}

\author{
Chen Zeying ${ }^{1}$, Subodh Kumar Sharma ${ }^{2}$, Amit K.Gupta ${ }^{3}$, P.K.Saini ${ }^{4}$ and N.K.Samria ${ }^{5}$ \\ ${ }^{1}$ Department of Information Engineering, Shenyang University of Chemical \\ Technology, Shenyang, Liaoning, China \\ ${ }^{2}$ Research Scholar, National Institute of Technology Kurukshetra, India \\ ${ }^{3}$ Associate Professor, Krishna Institute of Engeneering and Technology, \\ Ghaziabad, India \\ ${ }^{4}$ Assistant Professor, National Institute of Technology Kurukshetra, India \\ ${ }^{5}$ Professor, Indian Institute of Management and Technology, Greater Noida, India \\ ${ }^{1}$ Db_czy@189.com, \\ ${ }^{2}$ Corresponding author: subodhmeerut@gmail.com
}

\begin{abstract}
Under steady-state, a thermal investigation has been taken to study operating temperatures and heat flow rate in the valves of an AVI diesel engine. Temperatures, temperature fields, and heat flow rate were measured under all four thermal loading conditions (full, thirdfourth, half, and no load) using FORCE-2 FE (finite element) software. Appropriate averaged thermal boundary conditions were set on different surfaces for the FE model. Results obtained in the engine valves revealed that in addition to heat transfer by convection and radiation from combustion gases, the temperature and heat flux distributions are considerably affected by heat conduction from the valve seat. Contours of temperature fields introduced were shown as well. Results show that the main cause of valve safety is valve deformation and great thermal stress. So it is feasible to further decrease the valve temperature with structure optimization. Measuring the temperature in different parts of the diesel engine, we can adjust the cooling, or we can improve the materials, or even we can improve the properties of the fuels. The FEA result provides effective theoretical evidence for further improving the valves' performance. The evaluation confirmed the significant variation previously observed between the various methods.
\end{abstract}

Keywords: Valve, Temperatures field, Heat flux, Temperature, Finite elements

\section{Introduction}

In the combustion chamber engines, some of the parts like cylinder head, cylinder liner, piston, and valve are the most thermal loaded parts because they are in direct contact with the flam. Due to this they losses their strength and slightly deform from their original state. So it becomes important to calculate the stress distribution to control the deformations within acceptable levels. The thermal stress and mechanical stress level depend on the distribution of temperature in the parts, thermal load, coefficient of thermal expansion, young modulus of elasticity, design of the parts, and cooling conditions. For the thermal design of internal combustion diesel engine valves, an accurate estimation of heat transfer for various locations

Article history:

Received (February 21, 2014), Review Result (April 2, 2014), Accepted (May 15, 2014)

Print ISSN: 2288-8969, eISSN: 2207-516X IJSBT

Copyright (C) 2014 GV School Publication 
is of vital importance. Heat transfer affects the performance, efficiency, and emissions, as well as the life of the engine components, such as pistons, rings, and valves. To control the thermal stresses and deformations within acceptable levels it is important to calculate the valve temperature distribution. Because of exposure to hot exhaust gases; the exhaust valve of an internal combustion engine is one of the most critical parts. The design of valves depends on many parameters, such as fluid dynamics of the exhaust gas, the fatigue strength of the valve material, oxidation characteristics of the valve material, exhaust gas behavior of the material at high temperature, the configuration of the cylinder head, the coolant flow, the shape of the exhaust port, etc. To obtain an optimum condition and accurate estimations of heat flow rates, the temperature distribution in valves is needed. Thermal analysis guides us to design and optimize the engine parts to estimate heat flow accurately and consequently prevents failure of the parts due to excessive stresses, fatigue, corrosion, etc. Numerous works have been carried out in the study of heat transfer correlation in internal combustion engines. Prasad and Samria (1990) have formulated a set of equations based on finite difference approximation of an aluminum alloy piston of a diesel engine. They have resulted with the help of isotherms, that with an increase in insulation coating, the temperature increases. EAdu-Nada et al. (2006) introduced thermodynamic analysis of SI Engines by a theoretical model of air standard otto cycle by implementing temperature depending on specific heat. Singh, V.P. et al. (1986) proposed a model to study the heat transfer in the cylinder and piston assembly. Sakhrich, A.et al. (2010) suggested that early injection timings lead to a higher level of pressure and temperature in the cylinder and found out the optimum equivalence ratio for different engines. Sharma, S.K. et al. (2013) introduced an air- cavity in a diesel engine valve to prevent heat loss without affecting the thermal stress. By making these cavity temperatures at all the nodes were dropped down without doing any thermal barrier coating on it. Kandil, A.et al. (1995) presents a complete evaluation of temperature and stress distribution, in a non-steady state, is obtained by a numerical model. In this model, the temperature of the inside surface of the thick-walled cylinder is considered to change according to certain boundary conditions. Prasad et al. (1990) carried out to assess the transient thermal response of the inlet and exhaust valves of a tata Mercedes, six cylinders, 4 strokes, water-cooled diesel engine with numerical calculations based on finite difference approximation. A detailed analysis has been given for estimating the boundary conditions of the inlet and exhaust valves of an IC engine.

The specific objective of this research paper was to develop an enhanced method to predict the temperature field and heat transfer from engine valves. This method should be supported by a research methodology comprising the application of thermodynamic principles and the fundamental equations of heat transfer. The justification for undertaking this research on heat transfer in engines is based on the potential benefits of this kind of investigation.

\section{Statement of the problem}

This thermal investigation is concerned with the diesel engine valve of the AV1 diesel engine, as shown in [Figure 1]. The engine is a single-cylinder, water-cooled engine. The compression ratios and - consequently - the power and the torque, are different. Selected technical data for the AV1 engine is provided in [Table 1]. In [Figure 1] the major diameter of the valve stem is $8 \mathrm{~mm}$, height is $110 \mathrm{~mm}$ and base diameter is $30 \mathrm{~mm}$. valves are made of alloy steel. The thermophysical materials properties and heat transfer parameters for four different cases of engine loading of the valves are given in [Table 2] and [Table 3]. In [Table 3], $\mathrm{T}$ and $\mathrm{H}$ represent the temperature and heat transfer coefficient, and subscript $\mathrm{g}, \mathrm{s}, \mathrm{ex}, \mathrm{b}$, 
and $\mathrm{f}$ represent the boundaries of the valve on the gas side (combustion chamber), valve seat side, exhaust gas side, bush contact surface side and fresh airside. With the help of these boundary conditions, temperature distribution will be analyzed in the valve.

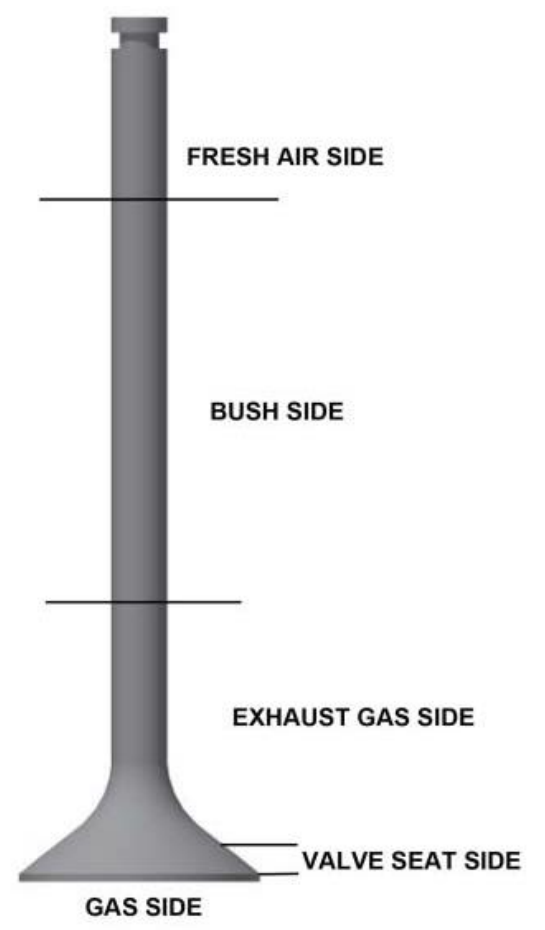

Figure 1. Diesel engine valve

\section{Development of a geometrical FE model}

A geometrical model of the valve was developed based on dimensions obtained from the actual object. In this model, a certain geometric simplification was assumed - including missed bends with a small radius on the edge of the lateral surface of the valve. Finally, the geometrical model was discretized into 3-node triangular finite elements. Such elements had to be applied due to the simple shape of the valve and good agreement with the axial symmetry. The size of finite elements was different in the respective sections of the valve.

Table 1. Engine and their specification

\begin{tabular}{|c|c|c|c|}
\hline Specification & Type & Specification & Type \\
\hline Cooling & Water-Cooled Engine & Governing & Class"B1" \\
\hline Model & AV1 & Power rating & 5 hp \\
\hline No. of Cylinders & 1 & Fuel injection & Direct Injection \\
\hline Cubic Capacity (ltr) & 0.553 & Rated Speed (rpm) & 1500 \\
\hline \multicolumn{2}{|c|}{ Overall Dimensions of the standard engine } & \multicolumn{2}{|c|}{617 X 504 X 843 (L X B X H) } \\
\hline
\end{tabular}


Table 2. Thermophysical properties of metal

\begin{tabular}{|c|c|c|c|}
\hline S.N. & Properties & Units & valve material (Alloy Steel) \\
\hline 1 & Thermal conductivity & $\mathrm{W} / \mathrm{m}^{2} \mathrm{k}$ & 50 \\
\hline 2 & Density & $\mathrm{Kg} / \mathrm{m}^{3}$ & 7850 \\
\hline 3 & Thermal diffusivity & $\mathrm{m} / \mathrm{hr}$ & 0.044 \\
\hline 4 & Specific Heat & $\mathrm{Kcal} / \mathrm{kg}^{0} \mathrm{c}$ & 0.113 \\
\hline
\end{tabular}

Table 3. Heat transfer parameter for four different cases of engine loading

\begin{tabular}{|c|c|c|c|c|}
\hline Parameter & Full Load & $3 / 4$ Load & Half Load & No Load \\
\hline \multicolumn{5}{|c|}{ Temperature in ${ }^{\circ} \mathrm{C}$} \\
\hline $\mathrm{Tg}($ Gas side) & 1000 & 800 & 600 & 400 \\
\hline $\mathrm{Ts}$ (Valve Seat side) & 300 & 120 & 120 & 120 \\
\hline $\mathrm{Ta}$ (Air side) & 25 & 25 & 25 & 25 \\
\hline $\mathrm{Tb}$ (Bush Side) & 80 & 80 & 80 & 80 \\
\hline $\mathrm{Tex}$ (Exhaust Gas side) & 290 & 270 & 250 & 230 \\
\hline \multicolumn{5}{|c|}{ Heat transfer coefficients $\left(\mathrm{W} / \mathrm{m}^{2} \mathrm{~K}\right)$} \\
\hline $\mathrm{Hg}($ Gas side) & 290 & 232.5 & 203.48 & 174.4 \\
\hline $\mathrm{Hw}$ (water side) & 1859.2 & 1859.2 & 1859.2 & 1859.2 \\
\hline $\mathrm{Ha}$ (Air side) & 23 & 23 & 23 & 23 \\
\hline $\mathrm{Hb}$ (Bush side) & 1745 & 1745 & 1745 & 1745 \\
\hline $\mathrm{Hex}$ (Exhaust Gas side) & 175 & 175 & 175 & 175 \\
\hline
\end{tabular}

\section{Thermal FE analysis}

To determine the temperatures, temperature field, and heat flow field due to the temperature variation in the valve, Finite Element Analyses (FEA) were carried out using FORTRAN force 2.0 versions with self-generating computational code. For this paper, use was made of the force 2.0 program which contains various subroutine programs based on heat transfer through conduction, convection, matrix multiplication, matrix inversion, heat flow, and stiffness. By using these subroutine and main programs, temperatures and heat flow field were calculated. Mathematical modeling of conduction equation, convection equation, and contact heat transfer equation has been done which are shown below. In the theory of finite element study, first, the proper variation principle is selected and then the function involved is expressed in terms of approximate assumed displacements, which satisfies the given boundary conditions. Then by minimizing the approximate function a set of governing equations is developed.

\subsection{Heat transfer equation for conduction}

The generalized governing differential equation for heat conduction can be represented as $[1,4]$ :

$$
\frac{\partial}{\partial \mathrm{X}}\left[\mathrm{K}_{\mathrm{X}}\left(\frac{\partial \mathrm{T}}{\partial \mathrm{X}}\right)\right]+\frac{\partial}{\partial \mathrm{Y}}\left[\mathrm{K}_{\mathrm{Y}}\left(\frac{\partial \mathrm{T}}{\partial \mathrm{Y}}\right)\right]+\frac{\partial}{\partial \mathrm{Z}}\left[\mathrm{K}_{\mathrm{Z}}\left(\frac{\partial \mathrm{T}}{\partial \mathrm{Z}}\right)\right]+\mathrm{q}_{\mathrm{E}}=\rho \mathrm{C} \frac{\partial \mathrm{T}}{\partial \tau}
$$


Where,

$\mathrm{K}_{\mathrm{X}}, \mathrm{K}_{\mathrm{Y}}, \mathrm{K}_{\mathrm{Z}}$ - Thermal conductivity in $\mathrm{X}, \mathrm{Y}$, and $\mathrm{Z}$ path respectively

$\mathrm{q}_{\mathrm{E}}-$ Heat conduction per unit volume

$\rho-$ Density of the material

C - Heat capacity of the material

For isotropic material, the thermal conductivity on all three directions are constant, i.e. $\mathrm{K}_{\mathrm{X}}, \mathrm{K}_{\mathrm{Y}}, \mathrm{K}_{\mathrm{Z}}=\mathrm{K}$

And in cylindrical coordinates;

$$
\nabla^{2} \mathrm{~T}=\frac{\partial^{2} \mathrm{~T}}{\partial \mathrm{r}^{2}}+\frac{1}{\mathrm{r}}\left(\frac{\partial \mathrm{T}}{\partial \mathrm{r}}\right)+\frac{1}{\mathrm{r}}\left(\frac{\partial^{2} \mathrm{~T}}{\partial \theta^{2}}\right)+\frac{\partial^{2} \mathrm{~T}}{\partial \mathrm{Z}^{2}}
$$

The variation integral in the axis-symmetric coordinate system can be represented as;

$$
\chi_{\mathrm{K}}^{(\mathrm{e})}=\frac{1}{2}(2 \pi \mathrm{K}) \iint_{\mathrm{A}}\left[\left[\frac{\partial \mathrm{T}}{\partial \mathrm{r}}\right]^{2}+\left[\frac{\partial \mathrm{T}}{\partial \mathrm{z}}\right]^{2}\right] \mathrm{rdrdz}
$$

The Polynomial selected in terms of shape function is given by

$$
t(r, z)=\left[\begin{array}{lll}
N_{I} & N_{J} & N_{K}
\end{array}\right]\left\{\begin{array}{c}
t_{i} \\
t_{j} \\
t_{k}
\end{array}\right\}=[N]^{(e)}\{t\}^{(e)}
$$

Where $\mathrm{N}$ is the shape function. Differentiating the above equation w.r.t coordinates $(\mathrm{r}, \mathrm{z})$

$$
\frac{\partial \mathrm{t}^{(\mathrm{e})}}{\partial \mathrm{r}}=\left[\begin{array}{lll}
\mathrm{b}_{\mathrm{i}} & \mathrm{b}_{\mathrm{j}} & \mathrm{b}_{\mathrm{k}}
\end{array}\right]\{\mathrm{t}\}^{(\mathrm{e})}=[\mathrm{b}]^{(\mathrm{e})}\{\mathrm{t}\}^{(\mathrm{e})}
$$

With the help of equation (5), the conductive matrix $\left(\chi_{\mathrm{K}}^{(\mathrm{e})}\right)$ becomes-

$$
\frac{\partial \chi_{\mathrm{k}}^{(\mathrm{e})}}{\partial\{\mathrm{t}\}^{(\mathrm{e})}}=\left(2 \pi \mathrm{KA}^{(\mathrm{e})} \mathrm{r}_{\mathrm{c}}\right)\left[[\mathrm{b}]^{(\mathrm{e})^{\mathrm{t}}}[\mathrm{b}]^{(\mathrm{e})}\right]+\left[[\mathrm{c}]^{(\mathrm{e})^{\mathrm{t}}}[\mathrm{c}]^{(\mathrm{e})}\right]\{\mathrm{t}\}^{(\mathrm{e})}
$$

Where

$$
\iint_{\mathrm{A}} \mathrm{rdrdz}=\mathrm{A}^{(\mathrm{e})} \mathrm{r}_{\mathrm{c},} \quad \mathrm{r}_{\mathrm{c}}=\frac{\mathrm{r}_{\mathrm{i}}+\mathrm{r}_{\mathrm{j}}+\mathrm{r}_{\mathrm{k}}}{3}
$$

Let $\mathrm{A}^{(\mathrm{e})} \mathrm{r}_{\mathrm{c}}=\mathrm{V}^{(\mathrm{e})}$; where $\mathrm{V}^{(\mathrm{e})}$ is the volume of an element.

$$
\frac{\partial x_{\mathrm{k}}^{(\mathrm{e})}}{\partial\{\mathrm{t}\}^{(\mathrm{e})}}=\left[\left[\begin{array}{lll}
\mathrm{k}_{11} & \mathrm{k}_{12} & \mathrm{k}_{13} \\
\mathrm{k}_{21} & \mathrm{k}_{22} & \mathrm{k}_{23} \\
\mathrm{k}_{31} & \mathrm{k}_{32} & \mathrm{k}_{33}
\end{array}\right]\left\{\begin{array}{l}
\mathrm{t}_{\mathrm{i}} \\
\mathrm{t}_{\mathrm{j}} \\
\mathrm{t}_{\mathrm{k}}
\end{array}\right\}=[\mathrm{k}]^{(\mathrm{e})}\{\mathrm{t}\}^{(\mathrm{e})}\right.
$$

Where $[\mathrm{k}]^{(\mathrm{e})}=$ stiffness matrix

\subsection{Heat transfer equation for contact boundary}

The universal governing differential equation for contact boundary can be represented as:

$$
\mathrm{q}_{\mathrm{c}}=\mathrm{K}_{1}\left[\frac{\partial \mathrm{T}}{\partial \mathrm{n}}\right]^{1}=-\mathrm{K}_{2}\left[\frac{\partial \mathrm{T}}{\partial \mathrm{n}}\right]^{2}
$$


Where, $q_{c}=h_{c}\left(T^{1}-T^{2}\right)$

Variation formulation for contact state line between 2 elements (e) and (p) can be written as-

$$
\begin{aligned}
& \chi_{\text {bcont. }}=\frac{\mathrm{h}_{\mathrm{c}}}{2} \int_{\mathrm{si}}^{\mathrm{sj}}\left[\{\mathrm{t}\}^{\mathrm{e}}-\{\mathrm{t}\}^{\mathrm{p}}\right]^{2} 2 \pi \mathrm{rds} \\
& \frac{\partial \chi_{\text {bcont. }}}{\partial\left\{\mathrm{t}_{\mathrm{s}}\right\}^{\mathrm{e}}}=\frac{2 \pi \mathrm{h}_{\mathrm{c}} \mathrm{r}_{\mathrm{m}} \mathrm{r}_{\mathrm{ij}}}{6 \cos \theta}\left[\begin{array}{cc}
2-\frac{\varepsilon}{2} & 1 \\
1 & 2+\frac{\varepsilon}{2}
\end{array}\right]\left\{\begin{array}{l}
\left\{\left\{\mathrm{t}_{\mathrm{s}}\right\}^{\mathrm{e}}-\left\{\mathrm{t}_{\mathrm{s}}\right\}^{\mathrm{p}}\right\}_{1} \\
\left\{\left\{\mathrm{t}_{\mathrm{s}}\right\}^{\mathrm{e}}-\left\{\mathrm{t}_{\mathrm{s}}\right\}^{\mathrm{p}}\right\}_{2}
\end{array}\right\}
\end{aligned}
$$

\subsection{Heat transfer equation for convective boundary}

The universal governing differential equation for heat convection can be represented as:

$$
-K\left(\frac{\partial T}{\partial \mathrm{n}}\right)=\mathrm{h}\left(\mathrm{T}-\mathrm{T}_{\infty}\right)
$$

The variational formulation for convective boundary can be represented as;

$$
\begin{gathered}
\delta \chi_{\text {bconv. }}=\int_{\mathrm{A}}-\mathrm{K}\left(\frac{\partial \mathrm{T}}{\partial \mathrm{n}}\right) \delta \mathrm{Td} S=\int_{\mathrm{A}} \mathrm{h}\left(\mathrm{T}-\mathrm{T}_{\infty}\right) \delta \mathrm{Td} S \\
\delta \chi_{\text {bconv. }}=\int_{\mathrm{i}}^{\mathrm{j}}-\mathrm{Kr}\left(\frac{\partial \mathrm{T}}{\partial \mathrm{n}}\right) \delta \mathrm{Td} \mathrm{S}
\end{gathered}
$$

Where $\mathrm{i}$ and $\mathrm{j}$ are the nodal points of the element of side $\mathrm{s}$.

$$
\begin{aligned}
& \text { Let } \frac{\mathrm{r}}{\mathrm{s}}=\cos \theta,\left(\frac{\partial \mathrm{T}}{\partial \mathrm{n}}\right)=\mathrm{h}\left(\mathrm{t}-\mathrm{t}_{\infty}\right) \text { and } \mathrm{ds}=\frac{\mathrm{dr}}{\cos \theta} \\
& \qquad \mathrm{T}(\mathrm{s})=\mathrm{N}_{\mathrm{si}} \mathrm{t}_{\mathrm{i}}+\mathrm{N}_{\mathrm{sj}} \mathrm{t}_{\mathrm{j}}=\left[\mathrm{N}_{\mathrm{s}}\right]\{\mathrm{t}\}
\end{aligned}
$$

Where $\mathrm{N}_{\mathrm{si}}$ and $\mathrm{N}_{\mathrm{sj}}$ are the shape factor.

$$
\begin{gathered}
\mathrm{N}_{\mathrm{si}}=\frac{s_{j}-\mathrm{s}}{\mathrm{s}_{\mathrm{ij}}}=\frac{\frac{\left(\mathrm{r}_{j}-r\right)}{\cos \theta}}{\frac{\mathrm{r}_{\mathrm{ij}}}{\cos \theta}}=\frac{\left(r_{j}-r\right)}{r_{i j}} \\
\mathrm{~N}_{\mathrm{sj}}=\frac{s-s_{i}}{s_{i j}}=\frac{\frac{\left(r-r_{i}\right)}{\cos \theta}}{\frac{r_{i j}}{\cos \theta}}=\frac{\left(r-r_{i}\right)}{r_{i j}}
\end{gathered}
$$

With the help of these equations $(15,16$ and 17) variational integral for convective boundary can be represent as

$$
\frac{\partial \chi_{\text {bconv. }}}{\partial\left\{\mathrm{t}_{\mathrm{s}}\right\}}=\frac{2 \pi \mathrm{hr}_{\mathrm{m}} \mathrm{r}_{\mathrm{ij}}}{6 \cos \theta}\left[\begin{array}{cc}
2-\frac{\varepsilon}{2} & 1 \\
1 & 2+\frac{\varepsilon}{2}
\end{array}\right]\left\{\begin{array}{c}
\mathrm{t}_{\mathrm{si}} \\
\mathrm{t}_{\mathrm{sj}}
\end{array}\right\}-\left\{\begin{array}{l}
\left(\mathrm{ht}_{\infty}\right)_{1} \\
\left(\mathrm{ht}_{\infty}\right)_{2}
\end{array}\right\}
$$


Where,

\section{Flow chart}

$$
\begin{gathered}
r_{m}=\frac{r_{i}+r_{j}}{2}, r_{i j}=r_{j}-r_{i}, r_{j}=r_{m}-\frac{r_{i j}}{2}, \varepsilon=\frac{r_{i j}}{r_{m}} \\
\frac{\partial \chi_{\text {bconv. }}}{\partial\left\{t_{s}\right\}}=[H]_{s}\{t\}_{s}-\left\{h t_{\infty}\right\}
\end{gathered}
$$

The following process is followed to examine the temperature and heat flow rate in the valve through the finite element method.

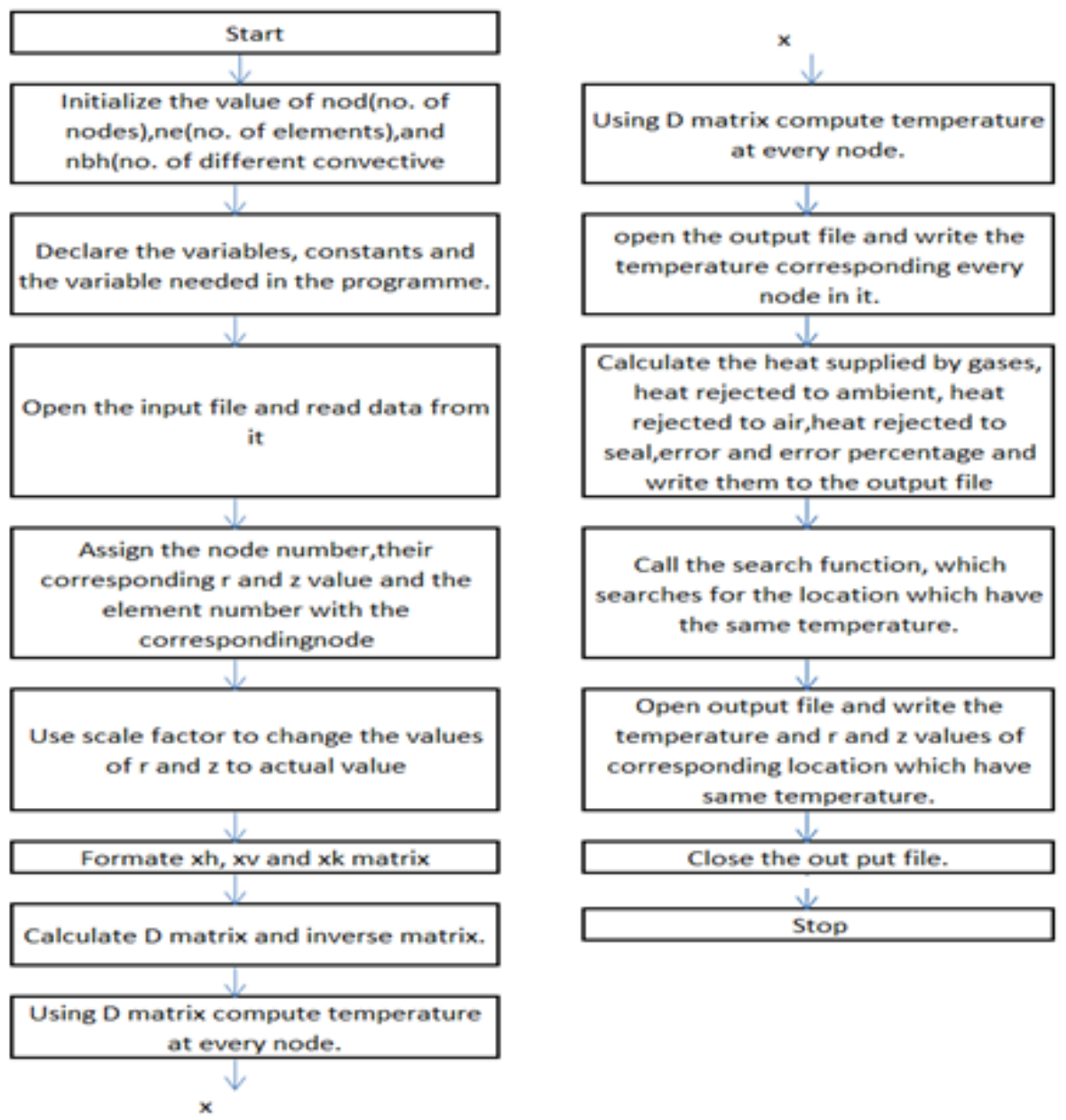

Step 1: Initially supply the value of nodes, elements, constants, different convective boundaries, and variables desired in the program.

Step2: Initialize the input data.

Step3: Use scale factor to modify the model node value to real node value.

Step4: Make the conductive, convective, and contact matrix and then develop D and DI matrix (D inverse matrix) with the help of input data (value of nodes, elements, constants, different convective boundaries, and variables) 
Step5: calculate the temperature at every nodal point with the use of the DI matrix.

Step6: Calculate the heat supplied by the gases to the valve $(\mathrm{Hg})$, heat rejects to air $(\mathrm{Ha})$, heat rejects to water $(\mathrm{Hw})$.

Step7: Search the nodal points which have the same temperature value, then plot the constant temperature (isotherms) line in the model.

\section{Temperature field calculation}

The prediction of the temperature distribution in the valves involves the resolution of the heat conduction and convection equation with the appropriate boundary conditions. For this purpose two-dimensional finite-element model for the valves modeling case was considered for steady-state engine operation. These models give satisfactory results with significant computer time economy.

Now from equations (8), (12) and (19), we can find the conduction, convection and contact boundary variational integral of heat transfer globally(for all the elements).

$$
\begin{gathered}
\frac{\partial\{\mathrm{X}\}^{\mathrm{g}}}{\partial\{\mathrm{t}\}^{\mathrm{g}}}=[\mathrm{K}]^{\mathrm{g}}\{\mathrm{t}\}^{\mathrm{g}}+[\mathrm{H}]^{\mathrm{g}}\{\mathrm{t}\}^{\mathrm{g}}-\left\{\mathrm{ht}_{\infty}\right\}^{\mathrm{g}}=0 \\
\text { Let }[\mathrm{K}]^{(\mathrm{g})}+[\mathrm{H}]^{\mathrm{g}}=[\mathrm{D}]^{\mathrm{g}} \\
\left\{\mathrm{ht}_{\infty}\right\}^{(\mathrm{g})}=\{\mathrm{V}\}^{(\mathrm{g})} \\
\{\mathrm{t}\}^{(\mathrm{g})}=[\mathrm{DI}]^{(\mathrm{g})}\{\mathrm{V}\}^{(\mathrm{g})}
\end{gathered}
$$

where $[\mathrm{DI}]^{(\mathrm{g})}=[\mathrm{D}]^{(\mathrm{g})^{-1}},\{\mathrm{t}\}^{(\mathrm{g})}$ global temperature.

The solution of the reduced steady-state heat conduction problem in the $\mathrm{r}, \mathrm{z}$ coordinate system is found by sub-dividing the quarter part of the valves into 117 elements and 89 nodes. Every element exists in thermal equilibrium with its neighboring elements. Generate computational code to solve mathematical model through FORTRAN language and find the temperature at all the nodes afterward draw temperature field (isothermal distribution curve) in the diesel piston model.

\section{Results}

The results of calculations carried out and have been presented in [Figure 2], [Figure 3], [Figure 4] and [Figure 5] show the temperature field (isothermal distribution) through the valves for four different engine loading conditions having resulting gas temperatures of $1000 \mathrm{oC}, 800 \mathrm{oC}, 600 \mathrm{oC}$, and $400 \mathrm{oC}$ respectively. The solid lines show the temperature field of valves. The result shows that there is a tendency to decrease the temperature fields in the valves as the thermal load decreases. The maximum and minimum temperatures in the valves occur at the bottom surface and the top surface, respectively, as shown in [Table 4]. From [Figure 2], [Figure 3], [Figure 4], and [Figure 5], it can be seen that valves receive heat from hot gases, which increases with an increase in engine loads. likewise, the heat gone to water, and heat gone to air, also increases with an increase in engine loads. [Table 5] shows the minimum and maximum value of heat transfer rate during the valve. [Figure 6] shows the variation of heat increase $(\mathrm{Qg})$ by the valve from the hot gases, heat gone to valve seat (Qs), the heat lost to incoming air $(\mathrm{Qa})$, and heat lost to valve bush $(\mathrm{Qb})$ at the four different thermal loading conditions. It seems that heat received from the hot gas is increased with an increase in the engine combustion temperature $(\mathrm{Tg})$. Similarly, the heat lost to the seat, the 
heat lost to the bush, and heat lost to air increases with engine combustion temperature. The temperature and heat transfer are obtained by indirect evaluation of the boundary conditions of the valve. The method presented may be used for other parts of I.C. engines such as the piston, cylinder heads, and cylinder wall, etc.

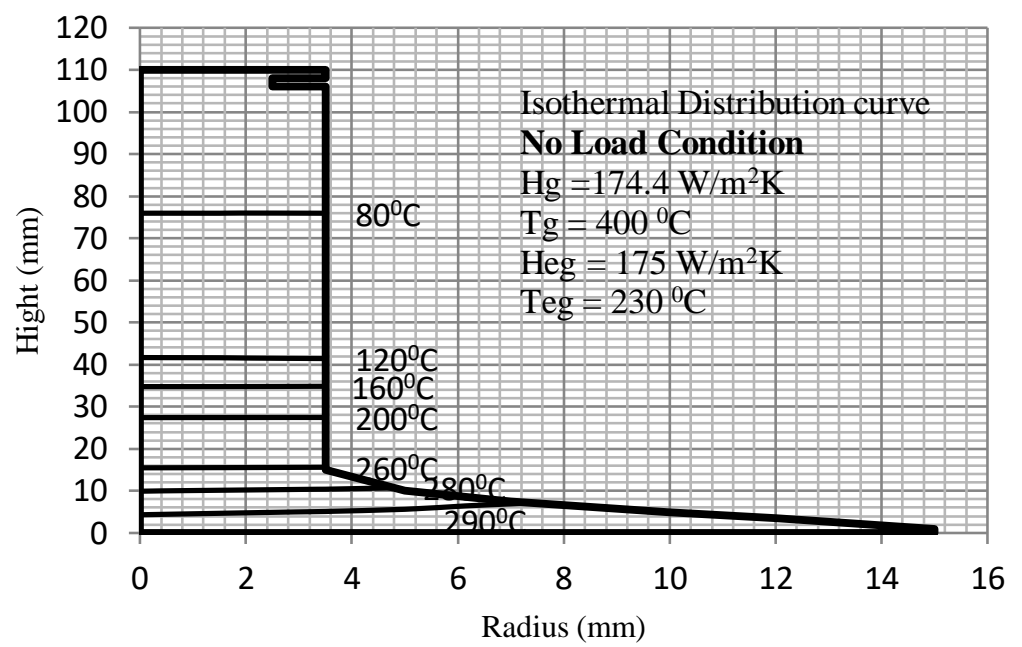

Figure 2. Isothermal curves at no load condition

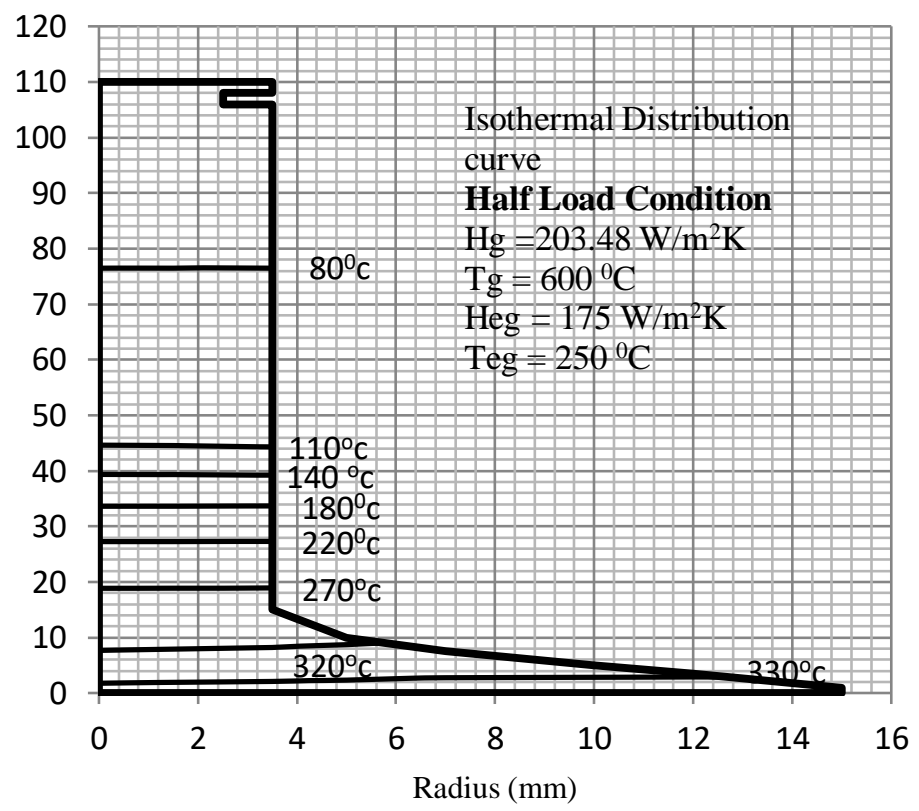

Figure 3. Isothermal curves at half load condition 


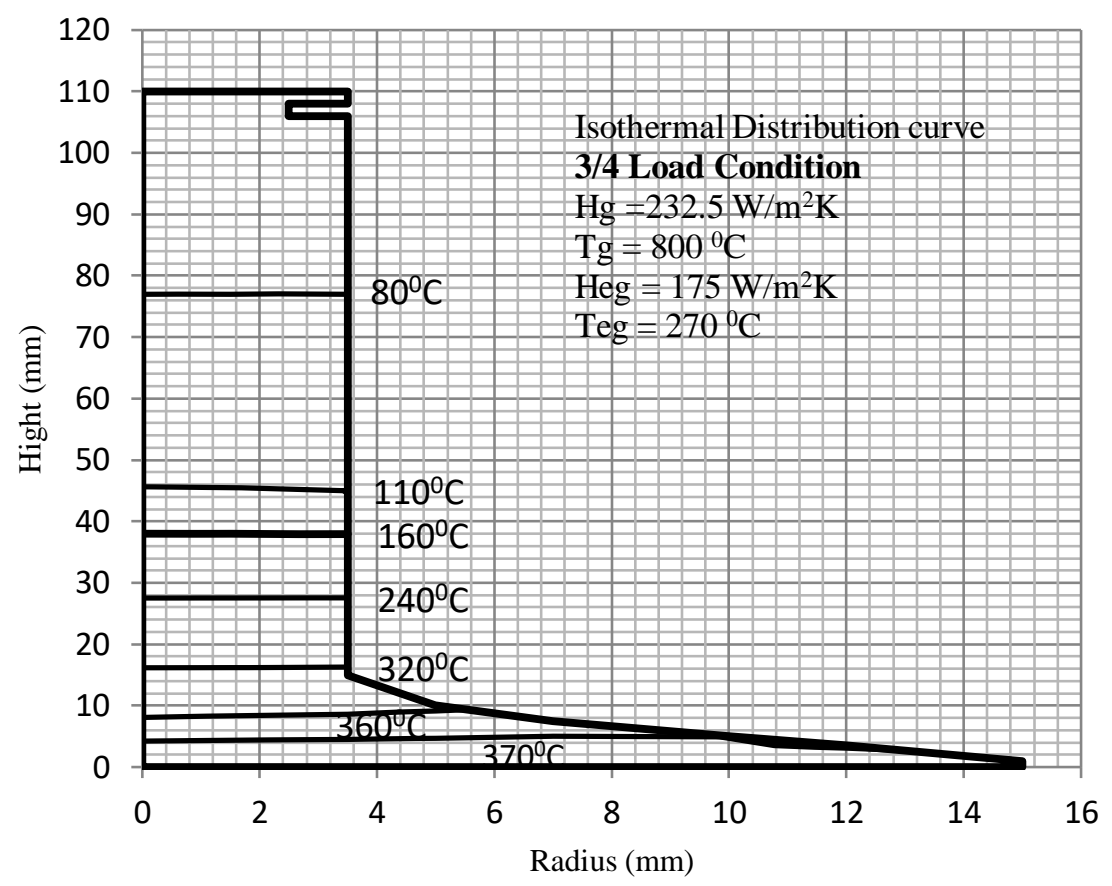

Figure 4. Isothermal curves at 3/4 load condition

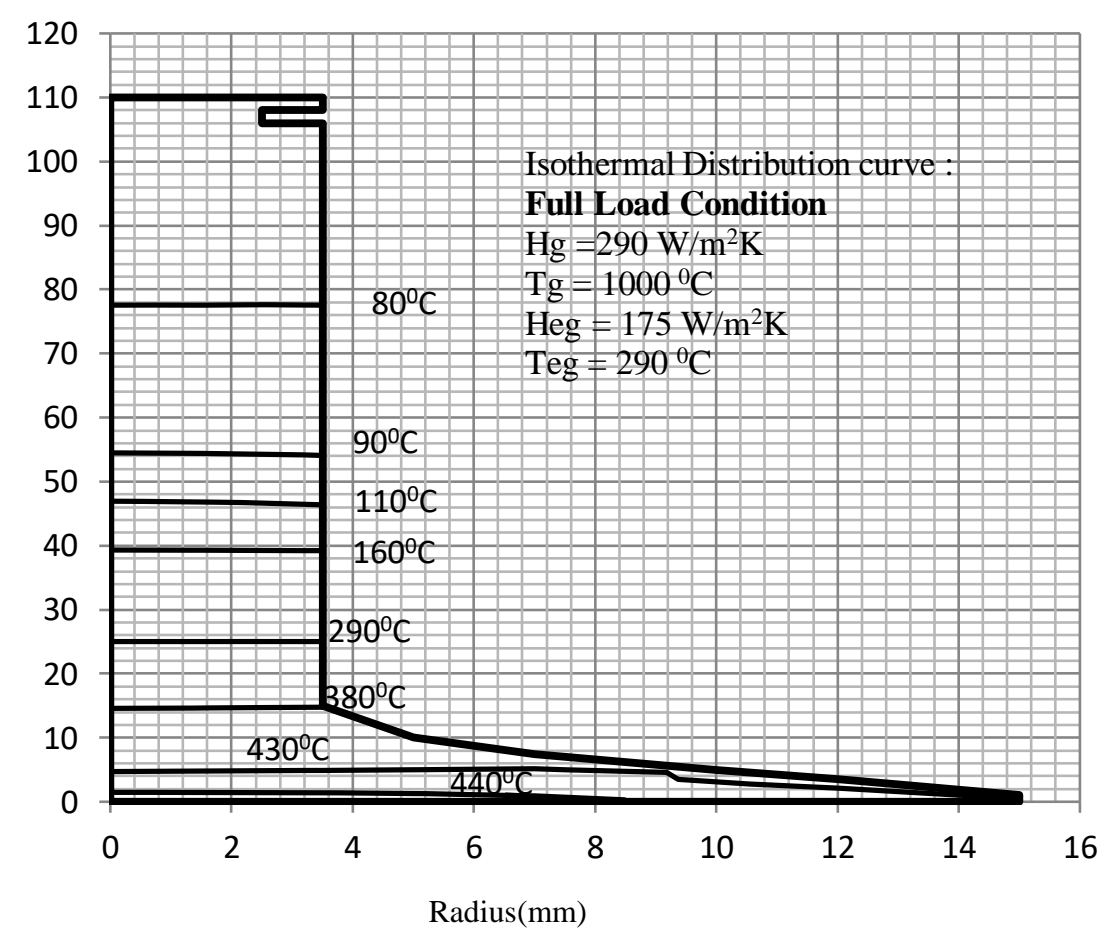

Figure 5. Isothermal curves at Full load condition 
Table 4. The maximum and minimum temperature in the valves

\begin{tabular}{|c|c|c|}
\hline Engine loading condition & $\begin{array}{c}\text { Max. Temperature } \\
\left({ }^{\circ} \mathrm{C}\right)\end{array}$ & Min. Temperature $\left({ }^{\circ} \mathrm{C}\right)$ \\
\hline Case 1 (No Load) & 290 & 80 \\
\hline Case 2 (Half Load) & 330 & 80 \\
\hline Case 3 (3/4 Load) & 370 & 80 \\
\hline Case 4 (Full Load) & 440 & 80 \\
\hline
\end{tabular}

Table 5. Maximum and minimum value of heat flow rate $(\mathrm{kW} / \mathrm{hr})$ in the valve

\begin{tabular}{|c|c|c|}
\hline \multirow{2}{*}{ Particulars } & \multicolumn{2}{|c|}{ heat flow rate (kW/hr) } \\
\cline { 2 - 3 } & Maximum & Minimum \\
\hline Qg (Gas Side) & 130.60616 & 14.41556 \\
\hline Qs (Seat Side) & 98.04006 & 0 \\
\hline Qb (Bush side) & 19.54745 & 12.43298 \\
\hline Qa (Air Side) & 12.43071 & 3.414 \\
\hline
\end{tabular}

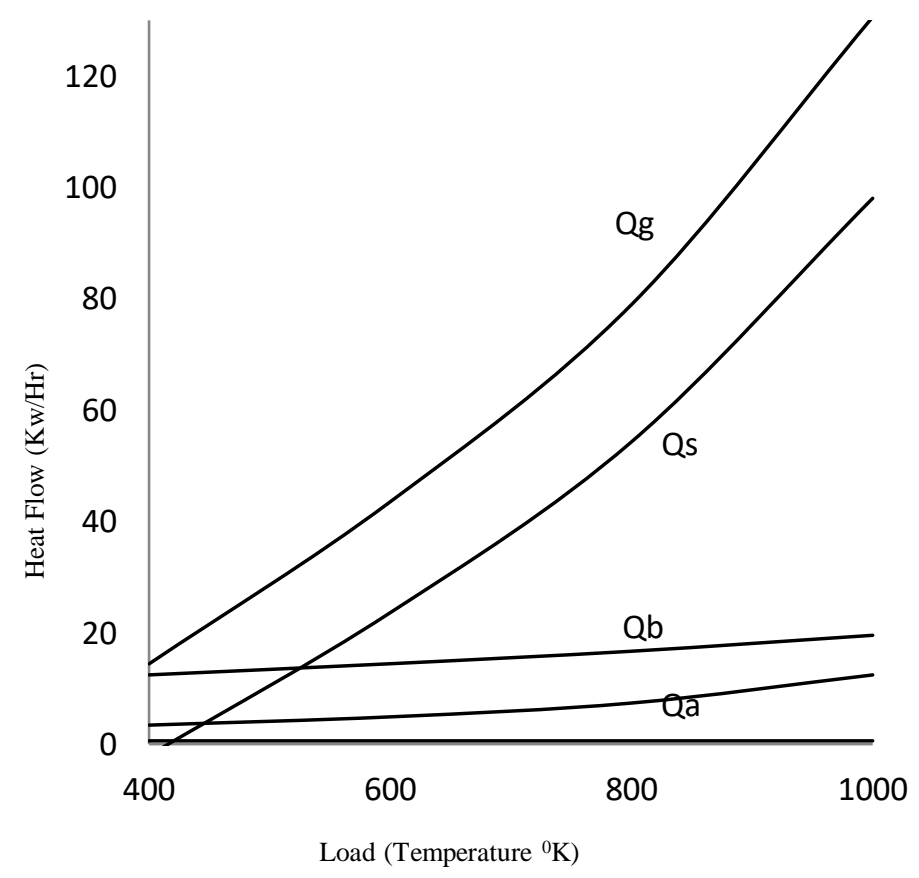

Figure 6. Heat flow pattern for four different load cases 


\section{Nomenclature}

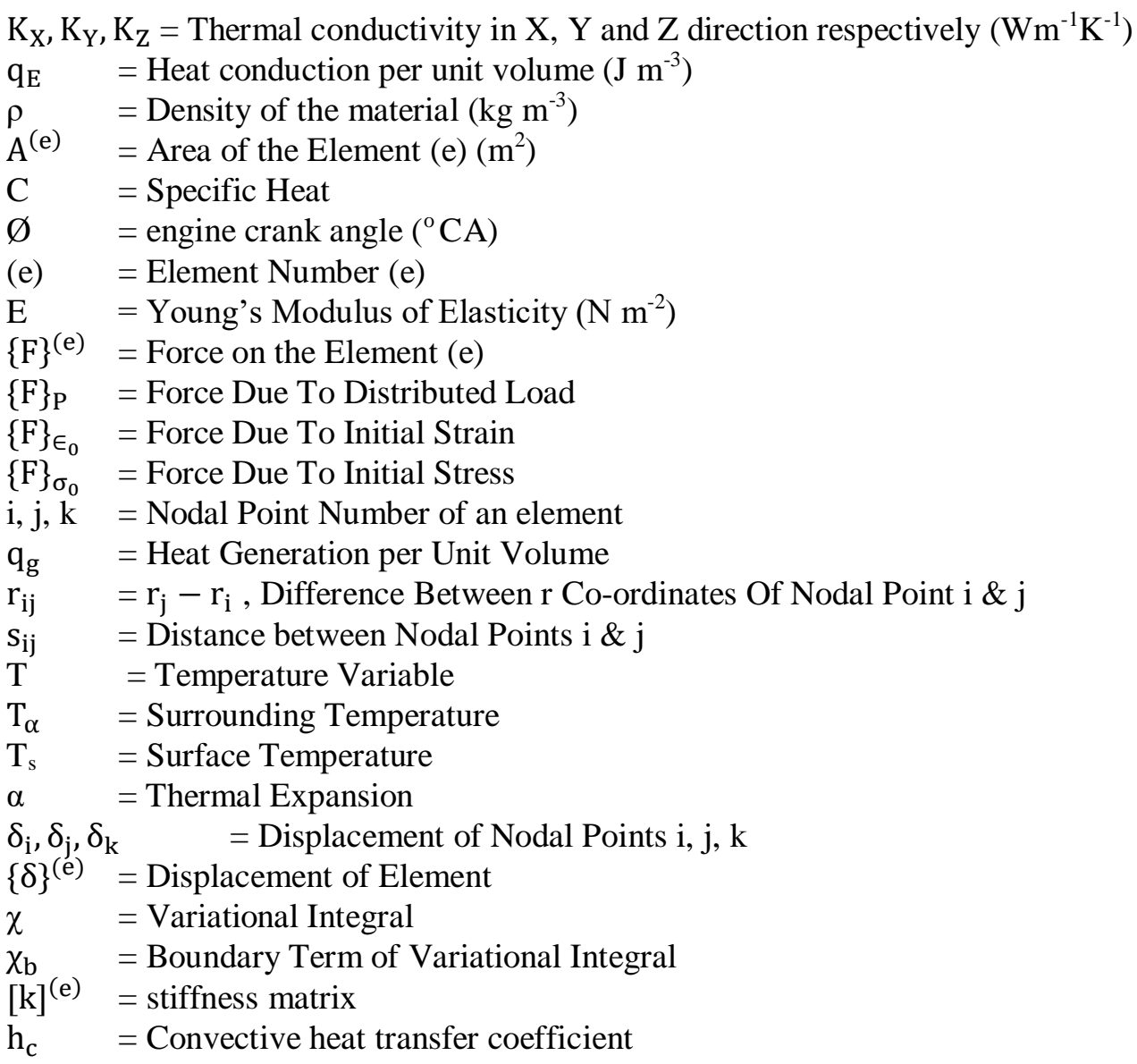

\section{References}

[1] G. Sitker, "Heat transfer and thermal loading in internal combustion engine", 2nd edition, Academia Kiado, Budapest

[2] R. Prasad, and N. K. Samria, "Heat transfer and stress fields in the inlet and exhaust valve of a semiadiabatic diesel engine", Computers \& Structures, vol.34, no.5, pp.165-711

[3] V. P. Singh, P. C. Upadhyay, and N.K. Samria, "Some heat transfer studies on a diesel engine piston", International Journal of Heat Mass Transfer, vol.29, no.5, pp.812-814

[4] R. Prasad and N. K. Samria, "Transient heat transfer analysis an internal combustion engine piston", Computers \& Structures, vol.34, no.5, pp.781-193

[5] A. Sakhrieh, E Abu-Nada, I. Al-Ghandoor, and B. Akash, "Computational thermodynamic analysis of compression ignition engine”, International Communication in Heat and Mass Transfer, vol.37, pp.299-303, (2010)

[6] M. Cerit, "Thermomechanical analysis of a partially ceramic coated piston used in an SI engine", Surface \& Coatings Technology, vol.205, pp.3499-3505, (2011)

[7] T.R. Kakuda, A. M. Limarga, D. Bennett and D.R. Clarke., "Evolution of thermal properties of EB-PVD 7YSZ thermal barrier coating with thermal cycling”, Acta Materialia, vol.57, pp. 2583-2591, (2009)

[8] A.G. Catto and A.T. Prata, "A numerical study of instantaneous heat transfer during compression and expansion in piston-cylinder geometry”, Numerical Heat Transfer, Part A, vol.38, pp.281-303, (2000) 
[9] K. Uzuneanu, T. Panait, and M. Dragan, "Modeling the heat transfer in the piston head of a spark ignition engine supplied with ethanol-gasoline blend”, COFRET'08, June 11-13, (2008)

[10] E. Abu-Nada, I. Al-Hinti, A. Al-Sarkhi, B. Akash, "Thermodynamic modeling of spark-ignition engine: Effect of temperature-dependent specific heats", International Communications in Heat and Mass Transfer, vol. 33, pp. 1264-1272, (2006)

[11] A. Kandil, A. A. El-Kady, and A. El-Kafrawy, "Transient thermal stress analysis of thick-walled cylinders", International Journal of Mechanical Science, vol. 37, pp.721-732

[12] T. T. Mon, R. Mamat and N. Kamsah, "Thermal analysis of SI Engine using simplified finite element model", WCE, vol. 3, July 6-8, (2011)

[13] B. Zhao, "Thermal stress analysis of ceramic coated diesel engine piston based on the wavelet finite element method", Journal of Engineering Mechanics, vol.138, no.1, (2012)

[14] S. K. Sharma, P. K. Saini, N. K. Samria, "Modelling and analysis of radial thermal stresses and temperature field in diesel engine valves with and without air cavity", International Journal of Engineering, Science and Technology, vol.5, no. 3, pp. 111-123, (2013) 
Computational Modeling for Thermal Analysis of AV1 Diesel Engine Valve using FEM

This page is empty by intention. 